\title{
Preparation and thermoelectric properties of K-doped p-type lead telluride
}

\section{K添加p型PbTeの作製と熱電特性}

\author{
Masaki ORIHASHI \\ Graduate School, Tohoku University, Aoba-ku Sendai 980-77, Japan \\ e-mail: orihashi@imr.tohoku.ac.jp \\ Yasutoshi NODA \\ Department of Materials Science, Faculty of Engineering, Tohoku University, \\ Aoba-ku Sendai 980-77, Japan TEL: +8122-217-7328 FAX: +8122-217-7328 \\ e-mail:nodayasu@argon.material.tohoku.ac.jp \\ Lidong CHEN and Toshio HIRAI \\ Institute for Materials Research, Tohoku University, Aoba-ku Sendai 980-77, \\ Japan TEL: +8122-215-2106 FAX: +8122-215-2107 \\ e-mail: cld@imr.tohoku.ac.jp \\ ( Received 8, November 1996 . Accepted 17, February 1997 )
}

Single crystals of $\mathrm{K}$-doped p-type $\mathrm{PbTe}$ were prepared by Bridgman method. The carrier concentration and Hall mobility were measured from 77 to $300 \mathrm{~K}$. The hole concentration was successfully controlled in the range from $8.0 \times 10^{24}$ to $4.0 \times 10^{25} \mathrm{~m}^{-3}$ with 1000 to 20000 molppm Kat $300 \mathrm{~K}$. By calculating $\kappa_{\mathrm{el}}$ on the basis of Fermi integration, $\kappa_{\mathrm{ph}}$ was estimated to be $2.15 \mathrm{Wm}^{-1} \mathrm{~K}^{-1}$.

By using the observed thermoelectric power and electrical conductivity value and the calculated $\kappa$ value, figure-of-merits $\mathrm{Z}$ of $\mathrm{PbTe}$ at $300 \mathrm{~K}$ were $8.0 \times 10^{-4} \mathrm{~K}^{-1}$ for $\mathrm{p}$-type at a hole concentration of $1.0 \times$ $10^{25} \mathrm{~m}^{-3} \quad(2000 \mathrm{molppm} \mathrm{K})$. The $\mu_{\mathrm{H}}$ monotonously decreased with an increase of carrier concentration. $Z$ remains low due to the low values of $\mu_{\mathrm{H}}$ and $\mu_{\mathrm{H}} / \kappa_{\mathrm{ph}}$.

Keywords: Lead telluride, p-type dopant, scattering mechanism, thermoelectricity, figure-of-merit, Fermi integral

\section{INTRODUCTION}

Lead telluride is among the best material used in construction of thermoelectric generators working at intermediate temperature $(450-840 \mathrm{~K})$. The PbTe generators were developed as the special application in space exploration in 1960s, and now constitute the power supply unit using heat of gas combustion.

The figure of merit $Z$ of $\mathrm{PbTe}$ reaches its maximum $Z_{\text {opt }}$ at a certain optimum temperature $T_{\text {opt }}$ and rapidly decreases on deviation from $T_{\mathrm{opt}}{ }^{1-3}$ The $T_{\mathrm{opt}}$ value of n-type $\mathrm{PbTe}$ is known to shift from low to high temperature with an increase of electron concentration.

Recently, an attempt to attain high conversion efficiency of PbTe thermoelectric material is based on the preparation of functionally graded material (FGM) carrier concentration. The carrier concentration has been controlled by doping iodine for n-type ${ }^{4}$ and $\mathrm{Ag}$ or $\mathrm{Na}$ for p-type, ${ }^{5,6}$ although the thermoelectric properties have not fully been clarified. 
The study for the homogeneous materials is indispensable to preparation and evaluation of the carrier concentration FGM of PbTe.

As a series of the study on $\mathrm{PbTe}$, the purpose of the present study was to investigate the thermoelectric properties for $\mathrm{K}$-doped p-type $\mathrm{PbTe}$ single crystals. The thermoelectric properties were analyzed on the basis of Fermi integration assuming the single valence band as the 0th approximation.

\section{EXPERIMENTAL}

The single crystals of $\mathrm{PbTe}$ were prepared by Bridgman method after direct melting of constituent elements of $\mathrm{Pb}$ and $\mathrm{Te}$ (nominal purity, 99.9999\%). The weighed amount of the elements in stoichiometric composition $(\mathrm{Pb} / \mathrm{Te}=1)$ was vacuum sealed in a quartz ample with metallic $\mathrm{K}$ as the p-type dopant. The ample was $10 \mathrm{~mm}$ in dia. and $120 \mathrm{~mm}$ in length, and the bottom end was shaped in a circular cone. The control of the doping amount was made by weighing $\mathrm{K}$ in the region of 1000 to 24000 molppm. The crystal growth was performed in the vertical electric furnace, where the maximum temperature was $1223 \mathrm{~K}$, and the temperature gradient was about 1200 $\mathrm{K} / \mathrm{m}$ at melting point. The growth rate was $4 \mathrm{~mm} / \mathrm{h}$.

The Hall coefficient $R_{\mathrm{H}}$ and electrical conductivity $\sigma$ were measured by van der Pauw configuration using the Pt-wire electrodes. The carrier concentration $\left|N_{\mathrm{A}}-N_{\mathrm{D}}\right|$ and Hall mobility $\mu_{\mathrm{H}}$ were calculated using the equation $\left|N_{\mathrm{A}}-N_{\mathrm{D}}\right|=1 / \mathrm{e} R_{\mathrm{H}}$ (e: electric charge) and $\mu_{\mathrm{H}}=R_{\mathrm{H}} \sigma$, respectively. The thermoelectric power $\alpha$ at $300 \mathrm{~K}$ was estimated from the linear relationship between thermoelectromotive force EMF and temperature difference within $5 \mathrm{~K}$.

The valence band of $\mathrm{PbTe}$ is rather complexed, for which single and two band models were proposed. ${ }^{7,8}$ The analysis of the thermoelectric properties was performed on the basis of Fermi integration by assuming a dominant single band for heavily doped $\mathrm{PbTe}$ as the 0th approximation. In the present study, we performed the analysis of thermoelectric properties of $\mathrm{K}$-doped p-type $\mathrm{PbTe}$ by calculating Fermi-Dirac integration.

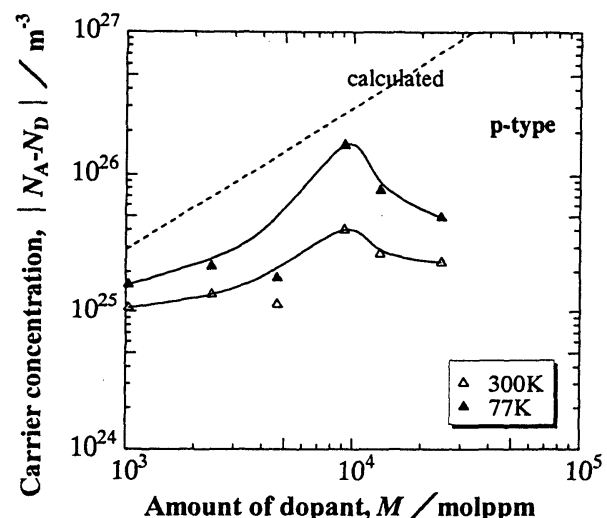

FIG.1. Plots of carrier concentration versus amount of dopant in K-doped p-type PbTe.

\section{RESULTS AND DISCUSSION}

\section{A.CONTROL OF CARRIER CONCENTRATION}

Figure 1 shows plots of carrier concentration versus amount $M$ of $\mathrm{K} .^{9}$ The dashed line is derived by assuming that the $\mathrm{K}$ atom occupies the $\mathrm{Pb}$ site and acts a singly ionizable acceptor. In the region of 1000 to 10000 molppm, the carrier concentration monotonously increased with an increase of doping amount, which was lower than that of the calculation. The hole concentration was successfully controlled in the range of $1.0 \times 10^{25}$ to $2.0 \times 10^{26} \mathrm{~m}^{-3}$ at $77 \mathrm{~K}$. The maximum carrier concentration was about $2.0 \times 10^{26}$ $\mathrm{m}^{-3}$ at $77 \mathrm{~K}$ and about $4.0 \times 10^{25} \mathrm{~m}^{-3}$ at $300 \mathrm{~K}$. The difference of carrier concentration between at $77 \mathrm{~K}$ and $300 \mathrm{~K}$ may be due to the contribution from heavy hole or decrease in mobility at temperature $T$ less than $300 \mathrm{~K}^{7}$ In the region of $M>10000$ molppm $\mathrm{K}$, carrier concentration decreased with an increase of $M$. The result suggests that interstitial $\mathrm{K}$ or $\mathrm{n}$-type precipitation may have caused carrier concentration or $R_{\mathrm{H}}$ increases because of inceasing of heavy hole density.

Figure 2 shows plots of $\mu_{\mathrm{H}}$ versus carrier concentration for $\mathrm{K}$-doped PbTe. The $\mu_{\mathrm{H}}$ value of all samples monotonously decreased with an increase of carrier concentration at 77 and $300 \mathrm{~K}$.

Figure 3 shows the temperature dependence of $\mu_{H}$ for $\mathrm{K}$-doped $\mathrm{PbTe}$, which indicates that $\mu_{\mathrm{H}}$ monotonously decreased with an increase of temperature.

Hall mobility $\mu_{н}$ is expressed in terms of 


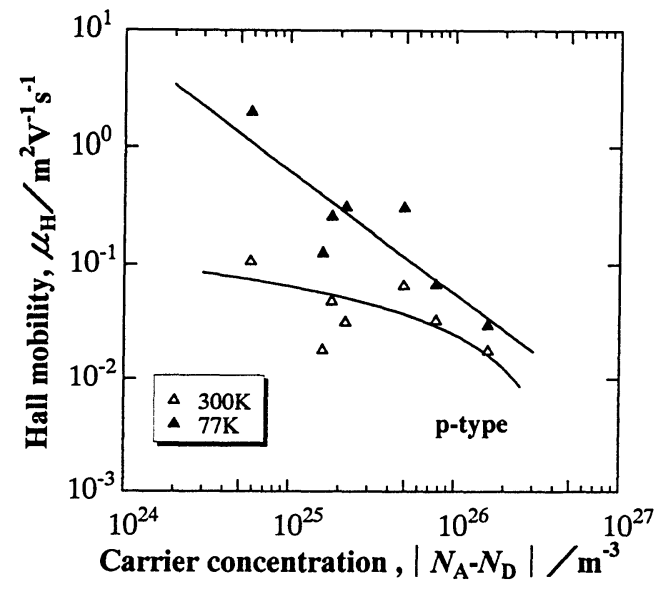

FIG.2. Plots of Hall mobility versus carreir concentration in K-doped p-type PbTe.

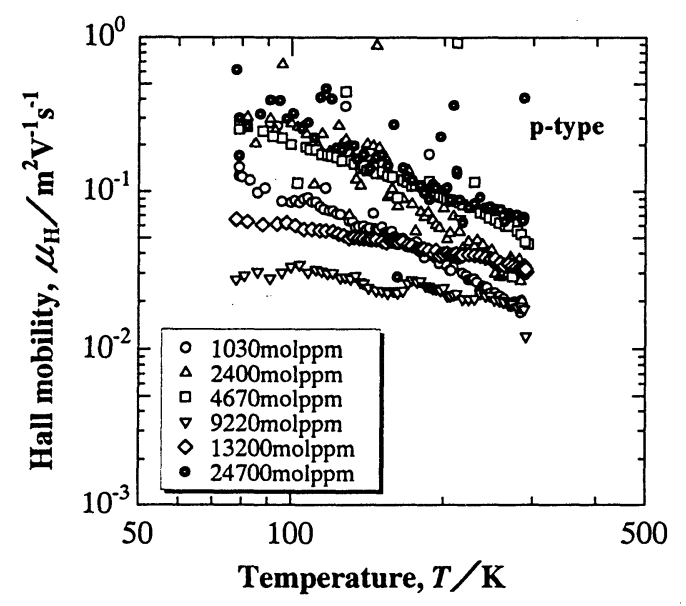

FIG.3. Temperature dependence of Hall mobility in $\mathrm{K}$-doped p-type $\mathrm{PbTe}$ (the numbers indicate amount of $\mathrm{K}$ in molppm).

temperature $T$ as follows; ${ }^{10}$

$$
\mu_{H} \propto T^{3 / 2+r} \text {, }
$$

where $\mathrm{r}$ is scattering factor, and $r=0$ and $r=3.0$ for acoustical and ionized impurity scattering, respectively.

As for K-doped $\mathrm{PbTe}, r$ was estimated to be changing from -0.17 to 0.95 with increased amount of dopant from 1000 to 25000 molppm. This result suggests that the scattering mechanism of the hole changed from phonon scattering to ionized impurity scattering with an increase of $M$.

Figure 4 shows plots of $\sigma$ and $\alpha$ versus carrier concentration. The $\alpha$ at 77 and $300 \mathrm{~K}$ value monotonously decreased and the $\sigma$ value increased

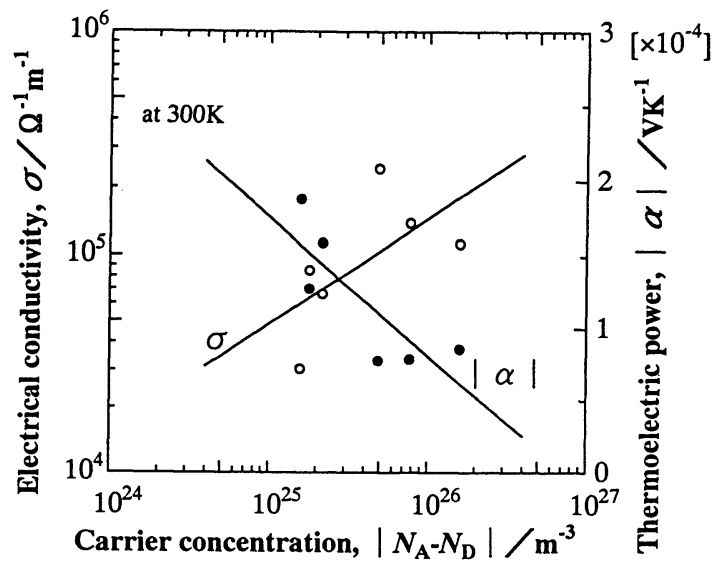

FIG.4. Plots of electrical conductivity versus carrier concentration in K-doped p-type PbTe.

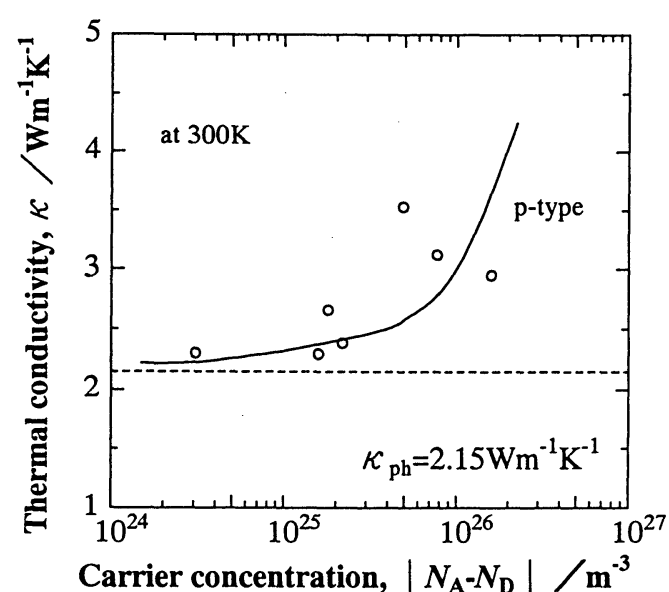

FIG.5. Plots of carrier concentration versus thermal conductivity in $\mathrm{K}$-doped p-type $\mathrm{PbTe}$.

with an increase of carrier concentration.

\section{B. ANALYSIS OF THERMOELECTRIC PROPERTIES}

The $K$ is expressed by the sum of components of phonon $\kappa_{\text {ph }}$ and electron $\kappa_{\text {el }}$ as follows, ${ }^{2,11}$

$$
\kappa=\kappa_{\mathrm{ph}}+\kappa_{\mathrm{el}} \text {. }
$$

$\kappa_{\text {el }}$ is expressed by the Wiedemann-Franz law, so that

$$
\kappa_{\mathrm{el}}=L \sigma T,
$$

where Lorentz number, $L$ is given by the following equation;

$$
\begin{gathered}
L=(k / e)^{2}\left[(r+3) /(r+1) F_{\mathrm{r}+2}(\xi) / F_{r}(\xi)-\right. \\
\left.\left\{(r+2) /(r+1) F_{r+1}(\xi) / F_{\mathrm{r}}(\xi)\right\}^{2}\right] .
\end{gathered}
$$




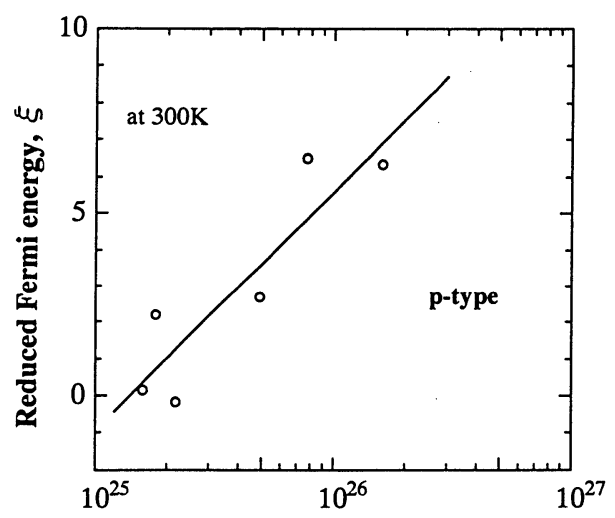

Carrier concentration, $\left|N_{\mathrm{A}}-N_{\mathrm{D}}\right| / \mathrm{m}^{-3}$

FIG.6. Plots of carrier concentration versus reduced Fermi energy in K-doped p-type PbTe.

Here $k$ is the Boltzman constant. $r$ is the scattering factor which was determined from the temperature dependence of Hall mobility. $\xi$ is the reduced Fermi energy $\left(=\xi \mid k T, \xi:\right.$ Fermi energy), $F_{r}(\xi)$ is the Fermi integral defined by ${ }^{12}$

$F(\xi)=\int_{0}^{\infty} x^{r} /\{\exp (x-\xi)+1\} d x$.

$\xi$ is expressed as follows;

$$
\alpha= \pm(k / e)\left\{(r+2) /(r+1) F_{r+1}(\xi) / F_{\mathrm{r}}(\xi)-\xi\right\} \text {, }
$$

where the positive and negative signs stand for the pand n-type conductions, respectively.

For the undoped p-type $\mathrm{PbTe}, \xi$ was calculated using the observed $\alpha$ and $r$ values. Thus, $\kappa_{\text {el }}$ was obtained by using calculated $L$ in eq.(4) and observed $\sigma$ value, which results in $\kappa_{\mathrm{ph}}$ to be $2.15 \mathrm{Wm}^{-1} \mathrm{~K}^{-1}$ on the basis of literature data of $\kappa$ value. ${ }^{13}$ Table 1 lists the $\kappa-, \xi$-, and $L$-values for undoped p-type $\mathrm{PbTe}$. The $\kappa_{\mathrm{ph}}$ value was hereafter assumed to be independent of the carrier concentration. Since $\kappa_{\text {el }}$ was calculated using eq.(3), the $\kappa$ values were estimated using $\kappa_{\mathrm{ph}}$ and $\kappa_{\mathrm{el}}$ as a function of the carrier concentration as shown in Fig. 5. The $\kappa$ value was found to increased monotonously with an increase of carrier concentration at 77 and $300 \mathrm{~K}$.

When the serious phonon scattering is taken into account for $\kappa_{\text {ph }}$ in heavily doped $\mathrm{PbTe}, \kappa$ value at high carrier concentration will not become so large as that in Fig. 5. The $\xi$ value in Fig. 6 monotonously increased from 0 to 7 with an increase of carrier concentration. The result indicates that $\mathrm{K}$-doped $\mathrm{p}$ -

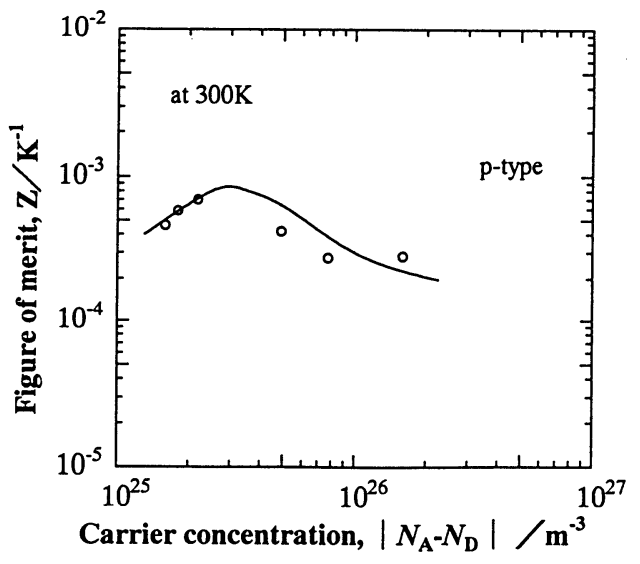

FIG.7. Plots of figure of merit versus carrier concentration in K-doped p-type PbTe.

type $\mathrm{PbTe}$ is heavily degenerated semiconductor. ${ }^{10}$

\section{EVALUATION OF THERMOELECTRIC FIGURE OF MERIT}

The thermoelectric figure of merit $Z$ was estimated from the observed $\alpha$ and $\sigma$ values using the equation;

$$
Z=\alpha^{2} \sigma / \kappa \text {. }
$$

Figure 7 shows plots of $Z$ value versus carrier concentration. The maximum figure of $Z(300 \mathrm{~K})=7.0$ $\times 10^{-4} \mathrm{~K}^{-1}$ was obtained at $p=2.34 \times 10^{24} \mathrm{~m}^{-3}$ (nominal doping concentration; 2000 molppm K)

The effective mass $m^{*}$ was estimated from the relationship, ${ }^{10,14}$

$$
p=4 \pi\left(2 m^{*}{ }_{d} k T\right)^{3 / 2} F_{1 / 2}(\xi) / h^{3},
$$

where $h$ is Plank constant, and $m_{d}^{*}$ is state of effective mass.

$m_{d}^{*}$ is given in the following expression in terms of $m^{*} ;{ }^{14}$

$$
m_{d}^{*}=N^{2 / 3}\left(m^{* 2}{ }_{\perp} m_{\|}^{*}\right)^{1 / 3},
$$

where $N$ is number of equivalent band edge ( $N=4$ for $\mathrm{PbTe}$ ), and the two components of effective mass are the longitudinal $m^{*} \|$ and transverse $m^{*}{ }_{\perp} \cdot m^{*}$ was calculated using eq.(9) on the hypothesis of $m^{*}=m_{\perp}^{*}$ $=m^{*} \|$. Table 2 lists effective mass ratio, $m^{*} / m_{0}\left(m_{0}\right.$ : free electron mass). The $m^{*} / m_{0}$ value for hole is consistent with the literature data. ${ }^{14}$

The maximum figure of merit $Z_{\max }$ is expressed in terms of the semiconducting parameters; ${ }^{14}$

$$
Z_{\max } \propto N m^{* 3 / 2} \mu T^{3 / 2} \exp (r+1 / 2) / \kappa_{\text {ph }} .
$$

Therefore $Z$ increases with an increase of the $m^{*}$ and 
mobility to thermal conductivity ratio $\mu / \kappa_{\mathrm{ph}}$. Table 2 shows semiconductive properties and maximum figure-of-merit of $\mathrm{K}$-doped PbTe at $300 \mathrm{~K}$. The $\mu_{\mathrm{H}}$ value was smaller than that of the literature data, ${ }^{14}$ and consequently the $Z$ and $\mu_{\mathrm{H}} / \kappa_{\mathrm{ph}}$ values were smaller than the literature data.

TABLE 1. Thermal conductivity and calculated values of carrier and lattice thermal conductivities of undoped $\mathrm{PbTe}$ at $300 \mathrm{~K}$.

\begin{tabular}{lcccc}
\hline \hline$\kappa$ & $\xi$ & $L$ & $\kappa_{\mathrm{el}}$ \\
$\left(\mathrm{W} \cdot \mathrm{m}^{-1} \mathrm{~K}^{-1}\right)$ & $\begin{array}{c}\left.\mathrm{N}^{-8} \mathrm{~V}^{2} \mathrm{~K}^{-2}\right) \\
\left(\mathrm{W} \cdot \mathrm{m}^{-1} \mathrm{~K}^{-1}\right)\end{array}$ & $\begin{array}{c}\kappa_{\mathrm{ph}} \\
\left(\mathrm{W} \cdot \mathrm{m}^{-1} \mathrm{~K}^{-1}\right)\end{array}$ \\
\hline 2.30 & -2.4 & 0.805 & 0.15 & 2.15 \\
\hline$\kappa$ :literature data ${ }^{13} \cdot$ & $\xi, L$ and $\kappa_{\mathrm{el}}$ were calculated in the present study using the observed $\alpha$ and $\mathrm{r}$ \\
values for an undoped p-type PbTe single crystal.
\end{tabular}

TABLE 2. Semiconductive properties and maximum figure-of-merit of $\mathrm{PbTe}$ at $300 \mathrm{~K}$.

\begin{tabular}{ccccccc}
\hline \hline Type & $\begin{array}{c}\text { Amount of dopant } \\
(\mathrm{molppm})\end{array}$ & $\mathrm{m}^{*} / m_{0}$ & $\begin{array}{c}\mu_{\mathrm{H}} \\
\left(10^{-4} \mathrm{~m}^{2} \mathrm{~V}^{-1} \mathrm{~s}^{-1}\right)\end{array}$ & $\begin{array}{c}\kappa_{\mathrm{el}} \\
\left(\mathrm{W} \cdot \mathrm{m}^{-1} \mathrm{~K}^{-1}\right)\end{array}$ & $\begin{array}{c}\mu_{\mathrm{H}} / \kappa_{\mathrm{ph}} \\
\left(10^{-2} \mathrm{mKW}^{-1} \mathrm{~V}^{-1} \mathrm{~s}^{-1}\right)\end{array}$ & $\begin{array}{c}Z_{\max } \\
\left(10^{-3} \mathrm{~K}^{-1}\right)\end{array}$ \\
\hline $\mathrm{p}$ & $2400(\mathrm{~K})$ & 0.301 & 310 & 0.24 & 1.44 & 0.70 \\
\hline
\end{tabular}

\section{CONCLUSION}

(1)The p-type PbTe single crystals were prepared by Bridgman method. The hole concentration was successfully controlled in the range of $8.0 \times 10^{24}$ to $4.0 \times 10^{25} \mathrm{~m}^{-3}$ with 1000 to 20000 molppm K at 300 $\mathrm{K}$. These data will be important in the further study on preparing the carrier concentration FGM of $\mathrm{PbTe}$. (2)By calculating $\kappa_{\text {el }}$ on the basis of Fermi integration, $\kappa_{\mathrm{ph}}$ was estimated to be $2.15 \mathrm{Wm}^{-1} \mathrm{~K}^{-1}$.

By using the observed $\alpha$ and $\sigma$ value and the calculated $\kappa$ value, $Z_{\text {max's }}$ were estimated to be $0.7 \times$ $10^{-3} \mathrm{~K}^{-1}$ at $p=1.0 \times 10^{25} \mathrm{~m}^{-3}$. The $Z_{\max }$ value was lower than those of the thermoelectric materials in the middle temperature range.

(3)The $\mu_{\mathrm{H}}$ monotonously decreased with an increase of carrier concentration. The low $\mu_{\mathrm{H}}$ and $\mu_{\mathrm{H}} / \kappa_{\mathrm{ph}}$ values cause the $Z$ value low-lying. The sintered$\mathrm{PbTe}$ might be effective to improve the $Z_{\max }$ by decreasing $\kappa_{\text {ph }}$ value.

(4)The detailed analysis of the thermoelectric properties is rest in the further studies by considering the valence band structure.

\section{ACKNOWLEDGMENTS}

The authors wish to thank Dr. I. A. Nishida for permitting us to utilize the computation system.

\section{REFERENCES}

1 I. B. Cardoff and E. Miler, Thermoelectric Materials and Devices, New York, Reinhold Publishing Co., (1960).

2 D. M. Rowe and C. M. Bhandari, Modern Thermoelectrics, Holt, Rinehart and Winston London, (1983).

${ }^{3}$ M. Niino and L.-D. Chen, Proc. 12th Int. Conf. Thermoelectrics ( X II -ICT), ed. Matsuura, Yokohama, 527 (1993).

${ }^{4}$ Y. Noda, M. Orihashi and I. A. Nishida, Trans. IEE of Japan, 116-A , 242 (1996).

${ }^{5}$ M. Battaglioli, V.Fano, G. Mignoni and Pergolari, Proc. 4th Int. Conf. on Thermoelectric Energy Conversion (ICTEC), Arligton, 114 (1982).

${ }^{6}$ R. W. Fritts, Lead Telluride Alloys and Junctions, Chap. 10 in Thermoelectric Materials

and Devices, New York, Reinhold Publishing Co., (1960). 
${ }^{7}$ R. S. Allgaier, and B. B. Houston, Jr. , W. W. Scanlon: J. Appl. Phys., 37, 302 (1966) .

${ }^{8}$ A. A. Andreev and V. N. Randionov, Fiz. Tekh. Poluprov., 1, 183 (1967). (Soviet Phys. - Solid State, 1, 145 (1967)).

${ }^{9}$ Y. Noda, M. Orihashi and I. A. Nishida, Proc. Symp. Thermoelectric Conversion '96 (TEC'96), 20 (1996).

${ }^{10}$ A. F. Ioffe, Semiconductors Thermoelements and Thermoelectric Cooling, Infoserch, London, (1958).

${ }^{11} \mathrm{~K}$. Uemura and I. A. Nishida, Thermoelectric Semiconductors and Their Applications, Nikkan
Kogyo, (1988).

${ }^{12}$ I .J. Ohsugi, T. Kojima and I. A. Nishida, J. Appl. Phys., 63, 5179 (1988).

13 Thermophysical Properties of Matter. vol.1, Thermal Conductivity Metallic Elements and Alloys, ed. by Y. S. Touloakian, R. W. Powell, C. Y. Ho and P. G. Klements, IF//PLENUM, New York, 1307 (1970).

${ }^{14}$ Yu. I. Rarich, B. A. Efimova and I. A. Smirmov, Semiconducting Lead Chalcogenides, Prenum Press, New York, (1970).

'96 SAS Intelligent Symposium 